\title{
Pengembangan dan Penerapan SMS Broadcast sebagai Media Penyaluran Informasi pada SD Negeri 1 Besakih
}

\author{
I Gusti Ayu Desi Saryanti ${ }^{1}$, Rosalia Hadi², Riza Wulandari ${ }^{3}$, Ni Luh Gede Pivin \\ Suwirmayanti ${ }^{4}$, Nyoman Ayu Nila Dewi ${ }^{5}$ \\ desi@stikom-bali.ac.id', rosa@stikom-bali.ac.id², rizawulandari@stikom- \\ bali.ac.id ${ }^{3}$, pivin@stikom-bali.ac.id ${ }^{4}$, nila@stikom-bali.ac.id ${ }^{5}$ \\ 1,2,3,4,5 Institut Teknologi dan Bisnis STIKOM Bali
}

\author{
Article History: \\ Received: 8-01-2022 \\ Revised: 10-01-2022 \\ Accepted: 12-01-2022
}

\begin{abstract}
Mass SMS or the term generall y called SMS Broadcast is a method of sending SMS to many numbers from one source or server with the same message content. Given its one-way nature, this type of SMS is very suitable to be used as a form of monitoring such as providing information to related parties. Partners in this activity are teachers or admins who record information to students or parents related to everything from the school. The location of internal service at this time is SD Negeri 1 Besakih. At this time there are still obstacles in the delivery of information as well as the use that is used to remember the location of this school is in the disasterprone area (KRB) of Mount Agung which at any time can cause the learning process to stop or the temporary location of teaching and learning to be moved. Based on the problems faced, training on the use of SMS Broadcast for teachers or school administrators was carried out which aims to facilitate and convey information to parents of students. For this reason, it is carried out in stages starting with socialization, and training on the application of SMS Broadcast.
\end{abstract}

Keywords: SMS Broadcast, Information Technology, Media Penyaluran Informasi

\section{Pendahuluan}

Kehidupan manusia yang bermula dari kesederhanaan kini menjadi kehidupan yang bisa dikategorikan sangat modern. Di era sekarang, segala sesuatu dapat diselesaikan dengan cara-cara yang praktis. Hal ini merupakan dampak yang timbul dari hadirnya teknologi. Teknologi adalah sesuatu yang bermanfaat untuk mempermudah semua aspek kehidupan manusia. (Jogiyanto, 2008). Dunia informasi saat ini seakan tidak bisa terlepas dari teknologi. Penggunaan teknologi oleh masyarakat menjadikan dunia teknologi semakin lama semakin canggih. Komunikasi memang diperlukan untuk menjalin suatu interaksi dalam masyarakat,syarat terjadinya interaksi harus adanya kontak dan komunikasi. Kontak tidak hanya terjadi secara berhadapan langsung, kontak dapat terjadi melalui perantara, perantara tersebut bias melalui peralatan. Oleh karena itu, orang dapat mengadakan hubungan komunikasi dengan orang lain tanpa harus bertemu, (Sendjaja, 2004). Secara sederhana kamus umum Bahasa Indonesia menjelaskan pengertian komunikasi sama dengan perhubungan. Melalui komunikasi orang dapat menyampaikan 
pesan-pesan tertentu kepada kelompok ataupun kepada masyarakat luas.

\section{SMS (Short Message Service) merupakan suatu teknologi yang} memungkinkan untuk mengirim dan menerima pesan antar pengguna mobile phone. (Gunawan, 2003) SMS gateway adalah suatu platform yang menyediakan mekanisme untuk EUA menghantar dan menerima SMS dari peralatan mobile (HP, phone, dan lain-lain) melalui SMS gateway short code. SMS gateway merupakan sistem aplikasi untuk mengirim dan/atau menerima SMS, terutama digunakan dalam aplikasi bisnis, baik untuk kepentingan promosi, servis kepada customer, pengadaan konten produk atau jasa, dan seterusnya. Hal ini merupakan sebuah aplikasi, maka fitur-fitur yang terdapat di dalam SMS gateway dapat dimodifikasi sesuai dengan kebutuhan. Perkembangan teknologi saat ini diyakini dapat mempermudah dari tindakan dan interaksi yang sejalan dengan pemanfaatan SMS sebagai media komunikasi (Primartha, 2014). Berdasarkan sekian banyak alat telekomunikasi telepon genggam saat ini menguasai kehidupan masyarakat. Mulai dari kalangan pelajar, industri, akad emisi bahkan bagi para pelaku ekonomi telah memiliki telepon genggam. Selain hemat efisiensi telepon genggam dapat memperkecil resiko bagi pemakainya. Melalui SMS Gateway Server, SMS dapat di broadcast/ blast/ bulk secara cepat dan efisien, sehingga pesan SMS promosi, SMS marketing, dapat segera diterima oleh pelanggan sehingga pihak pengiklan tidak perlu menghabiskan waktu dengan mengirimkan SMS satu per satu kepada pelanggannya. SMS juga sudah mulai dipergunakan untuk berhubungan antara seseorang dengan sebuah sistem sesuai dengan kebutuhan (Daud Tarigan, 2011).

SMS Broadcast adalah jenis layanan SMS yang bersifat satu arah yang dikirim kebanyak nomor tujuan hanya dengan satu kali klik dari komputer anda, dan yang menjadikan SMS Broadcast menjadi unik selain dapat mengirimkan SMS dalam jumlah besar (Adil, 2009). Istilah lain untuk SMS Broadcast ini adalah SMS bulk, SMS masal, SMS lewat internet atau SMS via internet. Banyak perusahaan atau instansi yang menggunaan jasa pengiriman SMS dari web ini, karena sistemnya sangat sederhana tetapi efektif.

Peserta pelatihan dalam kegiatan ini adalah guru atau admin SD Negeri 1 Besakih yang bertugas dalam menyampaikan segala informasi kepada siswa atau orang tua siswa. Guru atau admin SD Negeri 1 Besakih memiliki latar belakang sebagai seorang tenaga pendidik. Sedikit diantara mereka yang paham akan keberadaan teknologi yang sebenarnya dapat membantu mereka dalam penyelesaian masalah-masalah yang ada salah satunya yaitu dengan penyebaran informasi dengan cepat menggunakan SMS Broadcast. Mereka sudah dapat menggunakan laptop atau komputer namun hanya sebatas pengetikan surat atau laporan-laporan yang lainnya. SD Negeri 1 Besakih ini merupakan salah satu sekolah yang berada di Desa Besakih, kecamatan Rendang Kabupaten Karangasem. Desa Besakih https://journal.universitasbumigora.ac.id/index.php/ADMA 
dapat dicapai dalam waktu kurang lebih 1 jam 30 menit dari kota Denpasar dan jarak sepanjang $52 \mathrm{~km}$.

Penyampaian informasi yang dilakukan oleh pihak sekolah saat ini masih secara manual yaitu hanya dengan menyampaikan langsung kepada para siswa atau menempel pengumuman di papan pengumuman. Kendala yang dihadapi belakangan ini oleh pihak sekolah dalam penyampaian informasi yang sifatnya mendadak. Hal ini dikarenakan sekolah ini berada pada kawasan rawan bencana (KRB) Gunung Agung yang pada saat itu seketika sekolah harus ditutup dan proses belajar mengajar dipindahkan ke lokasi yang dianggap aman. Namun dari pihak sekolah terkendala untuk memberikan informasi lokasi sekolah sementara atau informasi yang berkaitan dengan pendidikan mengingat lokasi siswa yang mengungsi berada pada daerah yang berbeda-beda namun proses belajar mengajar harus tetap dilakukan agar siswa tidak tertinggal pelajaran. Untuk itu akan diberikan pelatihan penggunaan SMS Broadcast kepada pihak sekolah yang ditujukan kepada orang tua siswa untuk menyampaikan informasi yang berkaitan dengan sekolah. Mengingat letak sekolah yang berada di pedesaan menjadi salah satu faktor penyebab kurangnya pengetahuan mengenai teknologi yang berkembang sangat pesat yang tentunya akan berdampak kepada ketertinggalannya akan perkembangan zaman. Kurangnya informasi serta pelatihan kepada guru atau admin ke lembaga sekolah yang berkaitan dengan pemanfaatan teknologi informasi terutama penggunaan SMS Broadcast yang tidak pernah ada dibayangan mereka. Berdasarkan hasil analisa terhadap situasi sekarang maka diketahui permasalahan prioritas mitra adalah Kurangnya pengetahuan guru terhadap manfaat SMS Broadcast. Tidak pernah adanya pelatihan atau sosialisasi untuk mengajarkan mereka menggunakan SMS Broadcast dalam penyaluran Informasi secara efektif dan efisien

\section{Metode}

Prosedur kerja dari kegiatan ini terdapat beberapa tahap yakni kegiatan ini dimulai dari sosialisasi kegiatan, pengembangan dan penerapan penggunaan SMS Broadcast, dan evaluasi kegiatan.

a. Sosialisasi dilaksanakan dengan menghadirkan peserta dalam pertemuan. Pada pertemuan tersebut akan disampaikan informasi-informasi mengenai latar belakang, target, sasaran dan tujuan kegiatan. Disamping menyampaikan maksud dan tujuan, juga dilakukan pencatatan data teknis lebih lanjut serta pencatatan visualisasi dalam bentuk video dan foto. Dokumentasi ini digunakan dalam desiminasi atau pemasyarakatan hasil pelaksanaan program.

b. Pelatihan pengunaan SMS Broadcast, untuk dapat menggunakan SMS 
Broadcast, akan digunakan alat bantu laptop, koneksi internet dan proyektor sehingga pelatihan akan dapat dilaksanakan. Dengan akses yang baik, maka proses pelatihan akan menjadi lebih efektif.

c. Evaluasi kegiatan dilakukan setelah pelatihan penggunaan SMS Broadcast dilakukan, evaluasi dilakukan dengan melihat hasil dari pembelajaran mereka dan tingkat penggunaan SMS Broadcast dengan berkunjung kembali ke sekolah.

\section{Pembahasan}

Pengabdian Masyarakat ini dilakukan dengan tujuan untuk membantu mitra dalam hal ini SD Negeri 1 Besakih yang bergerak dalam bidang Pendidikan dalam memberikan informasi kepada orang tua mahasiswa secara cepat. Serta memperkenalkan penggunaan dan peran penting Teknologi Informasi dalam memasarkan Dunia Pendidikan. Pada pembahasan ini akan menjelaskan bagaimana dari tahap awal dilakukan yaitu sosialisasi kepada mitra, penerapan dan pengembangan menggunakan SMS Broadcast serta monitoring dan evaluasi dari kegiatan pengabdian masyarakat tersebut dilakukan.

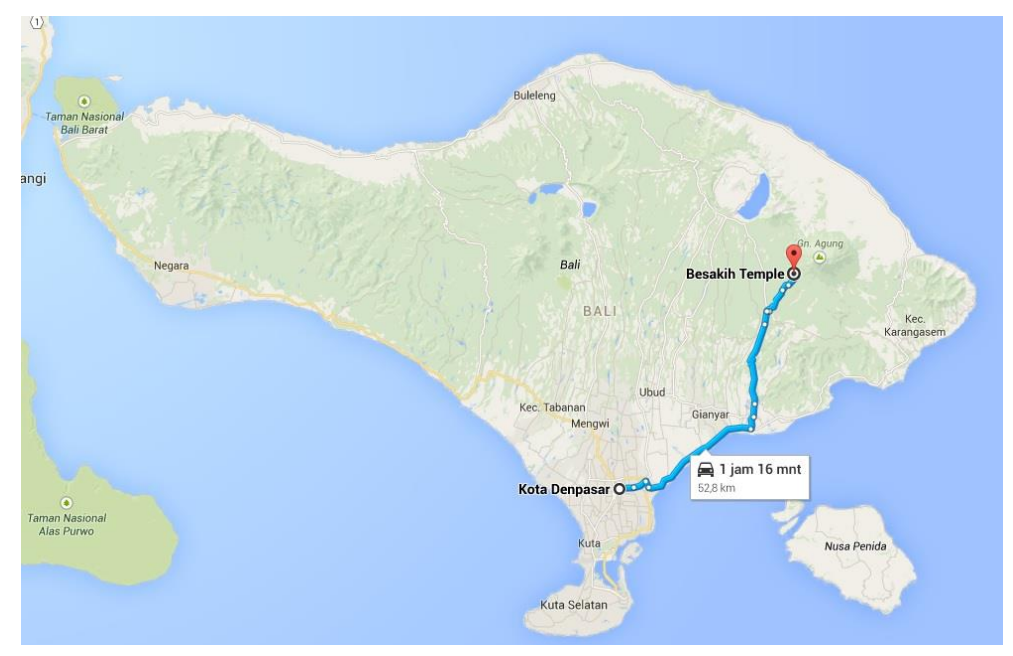

Gambar 1. Peta lokasi mitra

Pelaksanaan pengabdian masyarakat ini dilakukan pada SD Negeri 1 Besakih yang bergerak pada bidang pendidikan yang berlokasi di Desa Besakih Rendang Karangasem. Tempat tersebut dapat ditempuh dalam waktu kurang lebih 1 Jam 30 Menit dari lokasi pengusul. Jarak yang di tempuh pengusul ke Lokasi dengan jarak 52 km.

Berikut ini adalah uraian mengenai pelaksanaan kegiatan berdasarkan susunan acara kegiatan yang telah dibuat, antara lain: 
1. Sosialisasi

Sosialisasi dilakukan dengan guru dan pegawai untuk menyampaikan informasiinformasi mengenai latar belakang, target, sasaran dan tujuan kegiatan, serta membahas mengenai jumlah peserta, peralatan dan tempat bimbingan pengembangan SMS Broadcast. Selain itu, mereka membahas mengenai konten dan konteks materi mengajar yang diinginkan disesuaikan kebutuhan.

\section{Pengembangan dan Penerapan Penggunaan SMS Broadcast}

Penerapan penggunaan SMS Broadcast tersebut dilakukan dengan interaksi dua sisi, dimana pada saat diskusi, peserta dapat langsung bertanya kepada instruktur. Penerapan SMS Broadcast ini berfokus pada dasar dan hal-hal pokok yang perlu diperhatikan dalam penggunaan SMS Broadcast, cara menggunakan SMS Broadcast. Adapun hasil pengembangan dan penerapan SMS Broadcast yang diberikan pada pihak Sekolah adalah

3. Data Siswa dan Wali siswa

Langkah pertama yang harus dilakukan adalah membuka menyiapkan file Excel untuk menyimpan data-data orang tua siswa terutama nomor telepon yang nantinya akan dipergunakan untuk mengirim pesan berupa SMS.

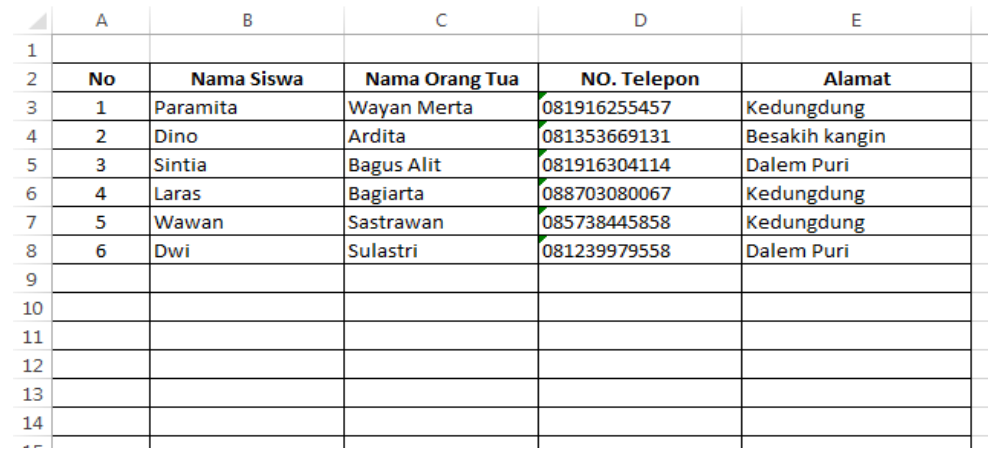

Gambar 1. Data orangtua siswa

\section{Aplikasi Robot SMS}

Aplikasi Robot SMS yang sudah terinstal pada laptop atau computer yang nantinya akan digunakan utuk pengiriman SMS. 


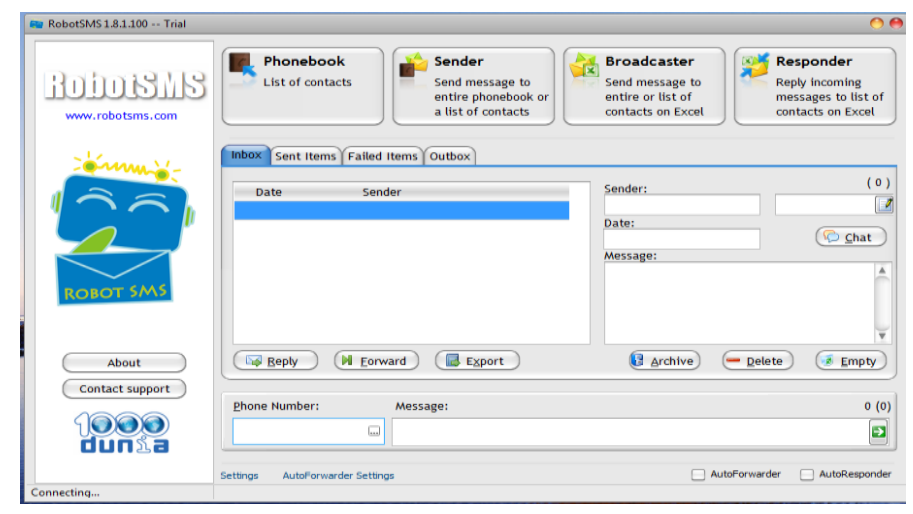

Gambar 2. Tampilan robot SMS

5. Penggunaan Aplikasi Robot SMS

Cara penggunaan aplikasi Robot SMS. Pertama-tama setelah tampilan Robot SMS terbuka kita pilih menu Broadcast.

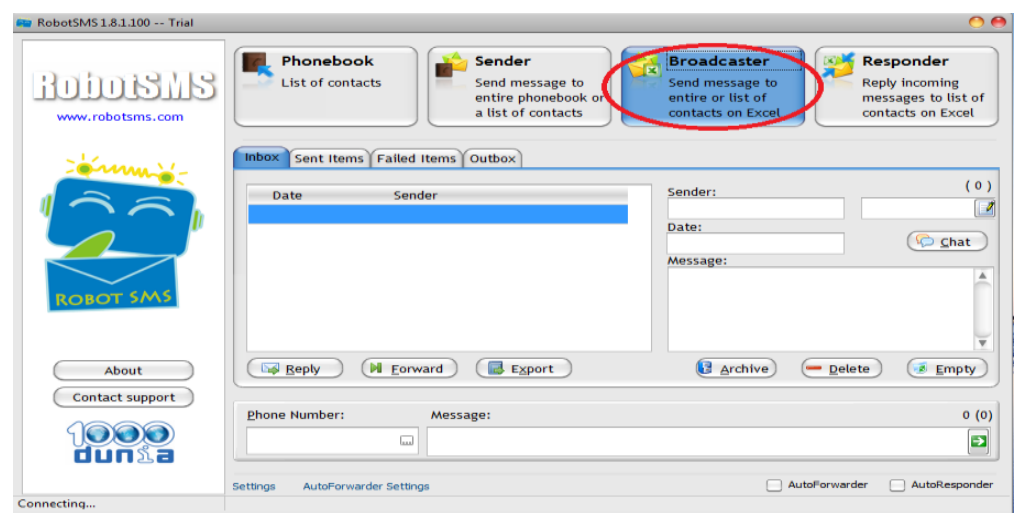

Gambar 3. Tampilan pilih Broadcast

6. Tampilan Halaman Broadcast

Dimana pada halaman ini akan diperintahkan untuk memasukkan file excel yang kita akan gunakan sebagai data untuk menyimpan data-data orang tua/wali siswa. Klik tombol open file $\left({ }^{*} . X L S\right.$

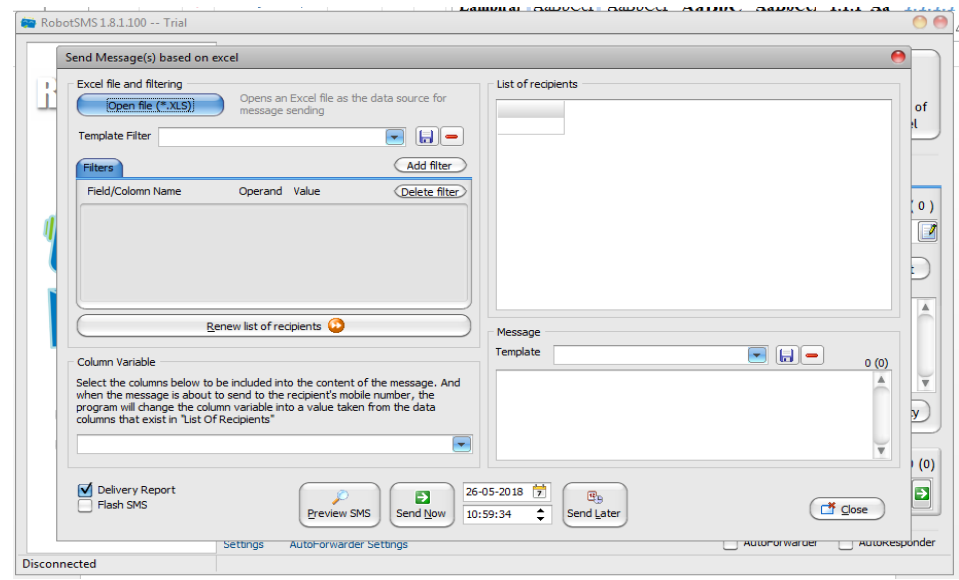

Gambar 5. Tampilan pilih file excel 
7. Tampilan File Excel yang digunakan

Pada tampilan ini kita akan mengisi beberapa bagian sesuai dengan file yang kita simpan seperti nama file, sheet berapa pada file tersebut dan nama kolom yang akan kita gunakan.

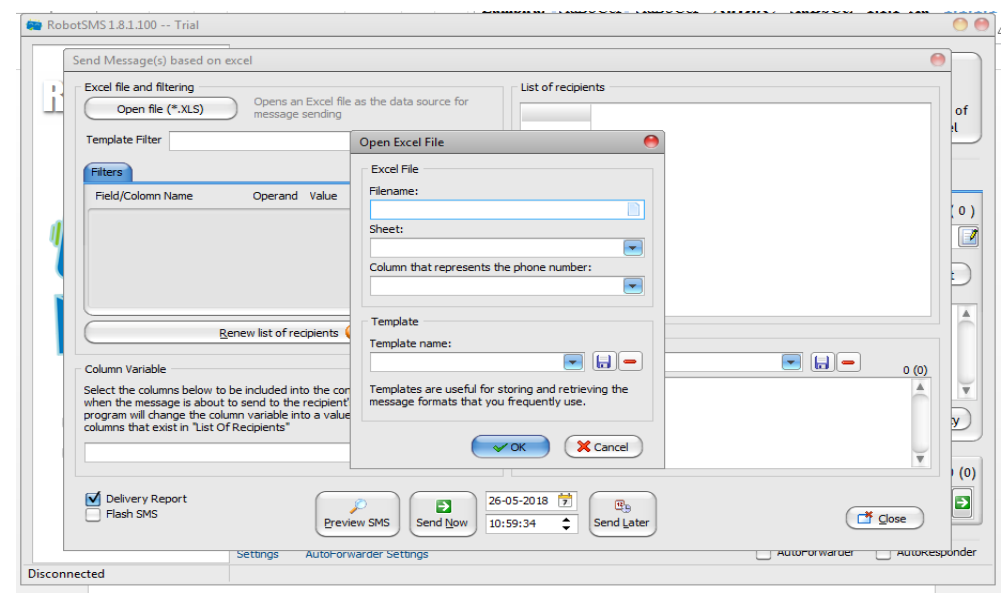

Gambar 6. Pilihan file excel yang digunakan

8. Tampilan Pengisian Nama File

Nama filenya disimpan pada data $D$ dengan nama Data Wali Siswa.xls, dberada pada sheet 1, nama kolom penyimpanan no. telepon yang akan dikirim SMS setelah semuanya lengkap tinggal tekan tombol OK.

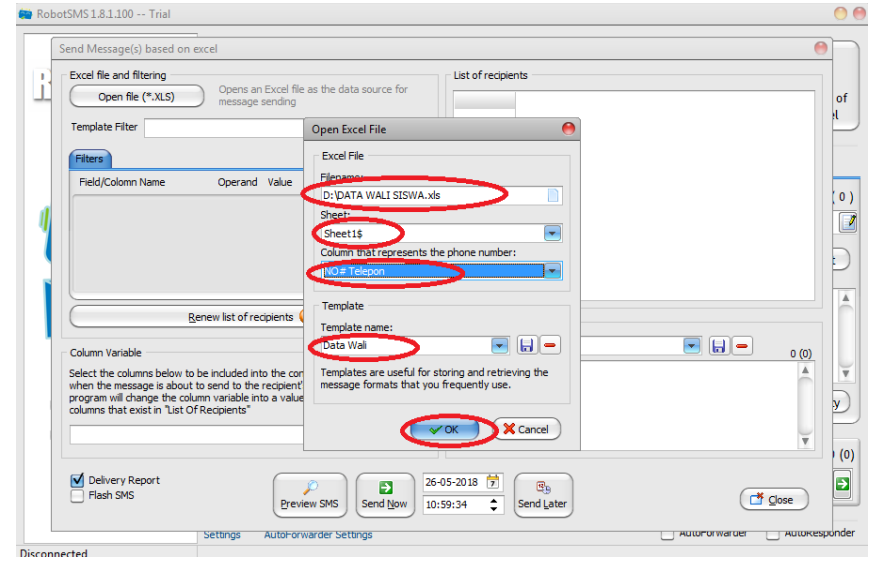

Gambar 7. Tampilan pengisian file

9. Tampilan Tahap Pengiriman SMS

Langkah ini merupakan tampilan saat sebelumnya memilih lokasi file penyimpanan data file excel data wali siswa. Pada tampilan ini kita akan memulai tahapan pengiriman SMS 


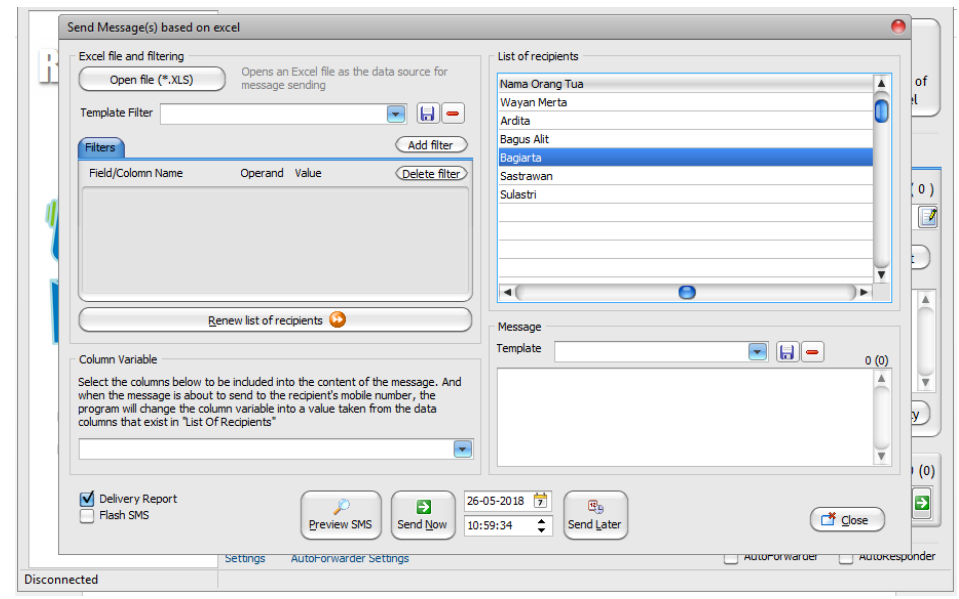

Gambar 8. Tahap pengiriman SMS

10. Penulisan SMS dengan Menyisipkan Variable

Langkah berikut merupakan cara penulisan SMS dengan menyisipkan nama orangtua agar setiap pengiriman SMS ke nomor yang dituju sesuai dengan nama pemilik nomor tersebut.

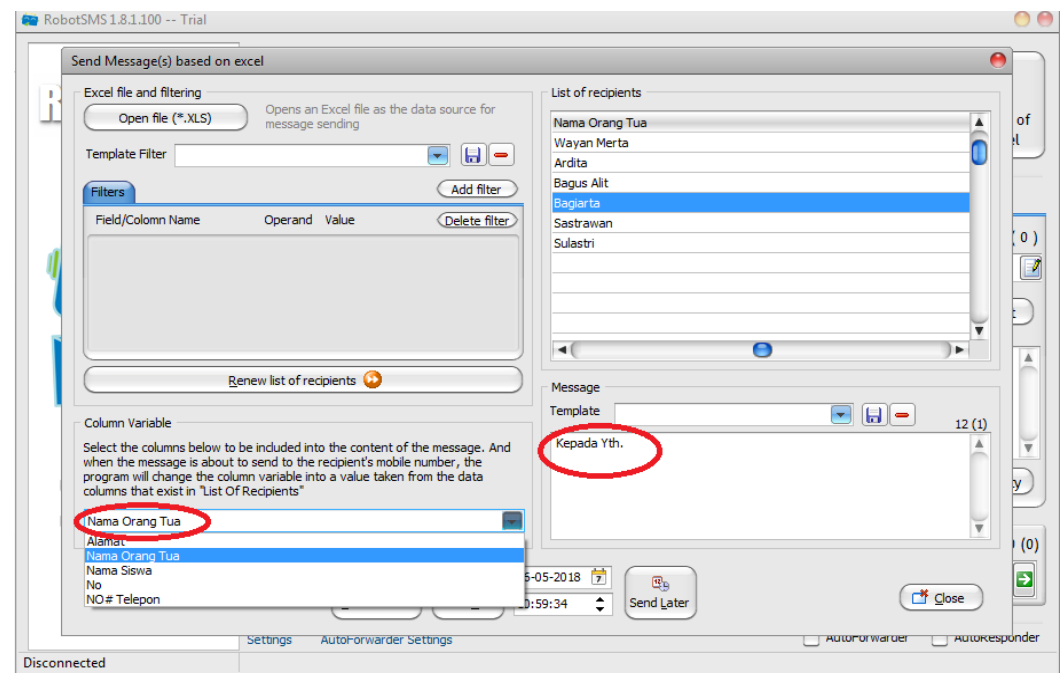

Gambar 9. Penulisan SMS dengan menyisipkan variabel

11. Tampilan pemilihan Variable

Langkah ini menunjukan bahwa ketika tadi mengetik Kepada Yth. Kemudian memilih variable Nama Orang Tua akan otomatis muncul pada halaman text. 


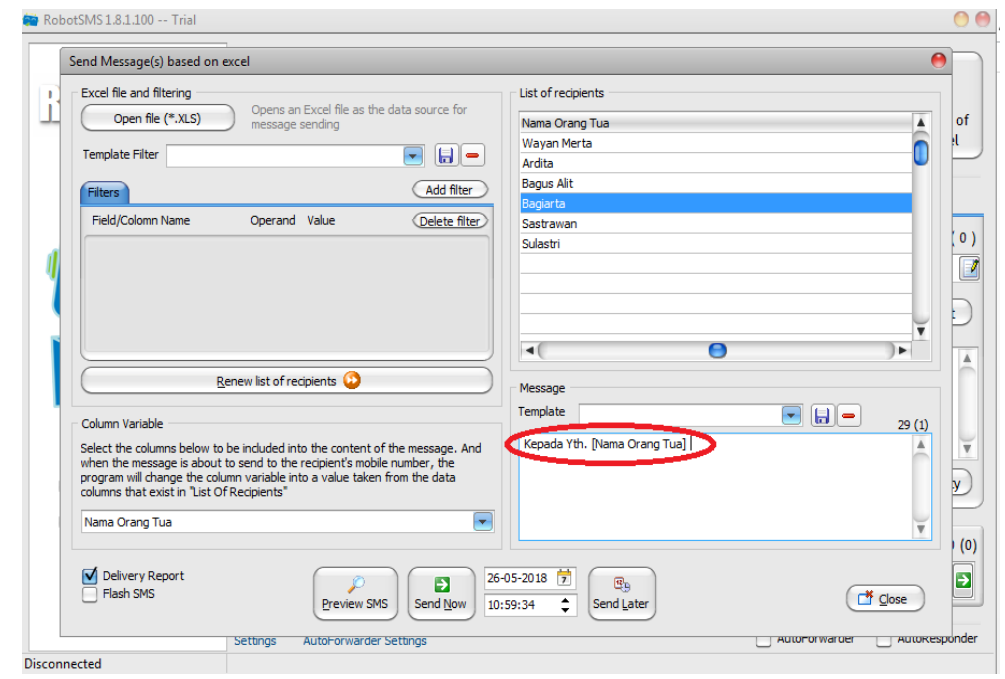

Gambar 10. Tampilan pemilihan variable

12. Tampilan Penulisan Text SMS

Kemudian kita dapat melanjutkan isi text yang akan dikirimkan kepada seluruh orangtua/ wali siswa sesuai dengan data yang tercantum pada file excel

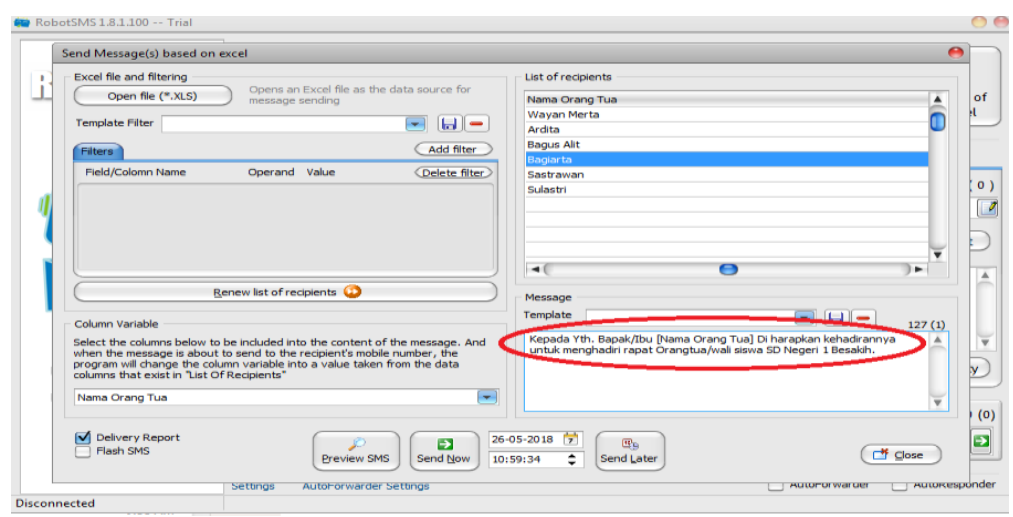

Gambar 11. Penulisan text SMS

13. Tampilan Preview SMS

Sebelum menekan tombol send Now kita dapat menekan tombol Preview SMS untuk memastikan pesan yang akan dikirim

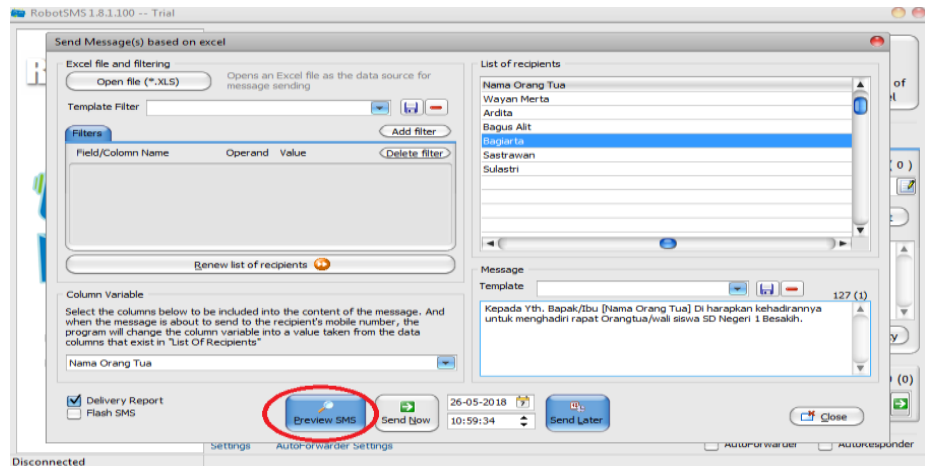

Gambar 12. Tampilan preview SMS 


\section{Tampilan Hasil SMS}

Dalam ini juga kita dapat melihat kalau nama orang tua yang kita masukan variable sudah sesuai dengan nama setiap orang tua yang tersimpan pada file excel. Sehingga setiap orang tua akan menerima pesan sesuai dengan nama mereka.

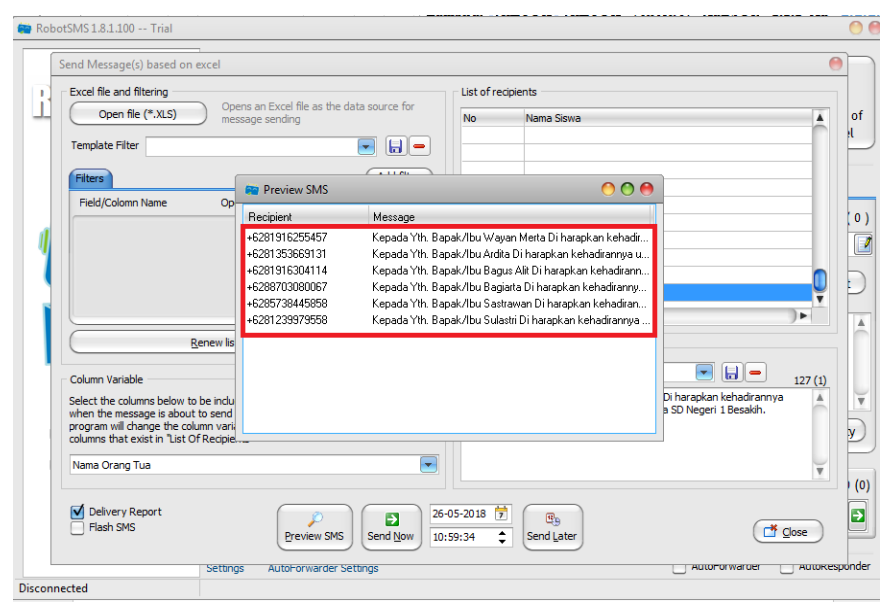

Gambar 13. Tampilan hasil SMS

15. Tampilan Pesan terkirim

Pada langkah ini memastikan SMS benar-benar terkirim ke seluruh nomor yang dituju. Kita tinggal menekan tombol outbox dan pesan yang sudah terkirim terlihat pada halaman ini.

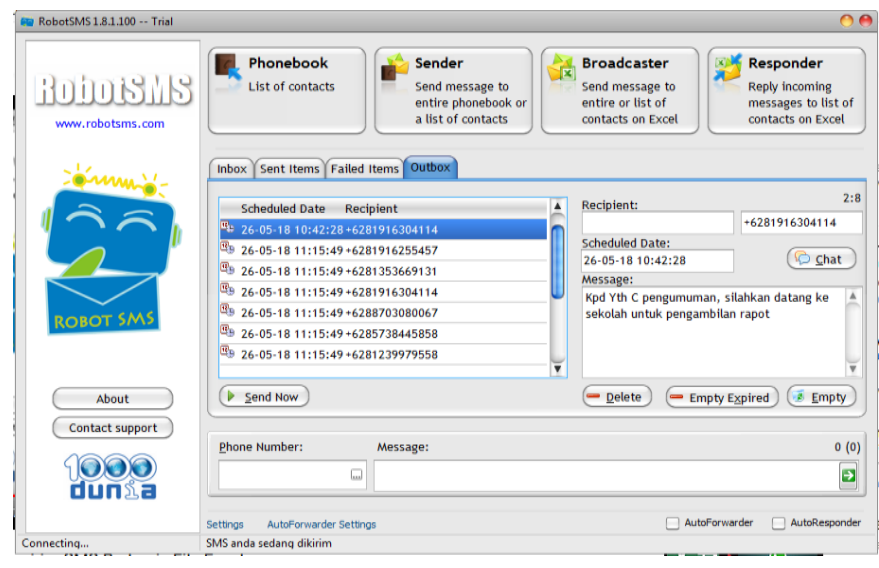

Gambar 14. Tampilan pesan terkirim

16. Monitoring dan Evaluasi

Monitoring dan evaluasi dilakukan dengan melihat, menilai, serta memberikan masukan berkaitan dengan hasil pengembangan penggunakan SMS Broadcast yang dihasilkan oleh peserta. Hasil presentasi tersebut sudah dibuat dengan sangat baik, terstruktur, serta fokus pada konteks dan konten yang diinginkan. 


\section{SIMPULAN}

Terdapat beberapa kesimpulan yang dapat diambil dari pelaksanaan pengabdian masyarakat yaitu pada dasarnya pihak sekolah belum pernah mengenal dan memahami penerapan SMS Broadcast sebagai media penyalur informasi yang membantu pihak sekolah dalam menyampaikan segala pengumuman kepada Orang Tua/Wali Siswa SD Negeri 1 Besakih. Pihak sekolah sangat tertarik dengan metode yang diberikan ini. Karena sangat efektif dan efisien dalam menyalurkan berbagai informasi terutama kepada para Orang Tua/Wali Siswa SD Negeri 1 Besakih. Selama ini pengumuman hanya disampaikan melalui surat yang dititipkan kepada siswa atau ditempel pada papan pengumuman, hal tersebut membuat rentannya kehilangan surat atau tidak tersalurnya informasi yang disampaikan. Dengan adanya SMS Broadcast ini pesan yang ingin disampaikan pihak sekolah dapat langsung ke tujuan yaitu Orang Tua/Wali Siswa.

\section{DAFTAR PUSTAKA}

Adil, R. (2009). Sistem Iformasi Via SMS Gateway Antar Pihak Kepolisian dengan Pengemudi. Jurnal Telkomnika, 7(2).

Daud Tarigan, E. (2011). Membangun SMS Gateway Berbasis Web dengan Codeigniter. Yogyakarta: Lokomedia.

Gunawan, F. (2003). Membuat Aplikasi SMS Gateway Server dan Client dengan Java dan PHP. Jakarta: PT. Elex Media Komputindo.

Jogiyanto. (2008). Analisis dan Desain Sistem Informasi : Pendekatan Terstruktur Teori dan Praktek Aplikasi Bisnis. Yogyakarta: Andi Offset.

Primartha, R. (2014). Sistem Informasi Hasil Pertandingan Pekan Olahraga Mahasiswa ASEAN ke-17 Berbasis SMS Gatewae. Konferensi Nasional Teknologi Informasi Dan Aplikasi (KNTIA14). Palembang.

Sendjaja, D. S. (2004). Pengantar Ilmu Komunikasi. Jakarta: Universitas Terbuka. 
